\title{
ANTIOXIDANT AND ANTIVIRAL PROPERTIES OF Pseudopiptadenia contorta (LEGUMINOSAE) AND OF QUEBRACHO (Schinopsis sp.) EXTRACTS
}

\section{Davyson de L. Moreira}

Faculdade de Farmácia, Centro Universitário de Barra Mansa, Rua Vereador Pinho de Carvalho, 267, Barra Mansa - RJ

Suzana G. Leitão

Departamento de Produtos Naturais e Alimentos, Faculdade de Farmácia, Universidade Federal do Rio de Janeiro, Centro de Ciências da Saúde, Bloco A, Ilha do Fundão, 21941-590 Rio de Janeiro - RJ

Jorge Luiz S. Gonçalves e Marcia D. Wigg

Departamento de Virologia, Instituto de Microbiologia Prof. Paulo de Góes, Universidade Federal do Rio de Janeiro, Centro de Ciências da Saúde, Bloco I, Ilha do Fundão, 21941-590 Rio de Janeiro - RJ

Gilda G. Leitão*

Núcleo de Pesquisas de Produtos Naturais, Universidade Federal do Rio de Janeiro, Centro de Ciências da Saúde, Bloco H, Ilha do Fundão, 21941-590 Rio de Janeiro - RJ

Recebido em 25/3/04; aceito em 29/9/04; publicado na web em 2/2/05

\begin{abstract}
ANTIOXIDANT AND ANTIVIRAL PROPERTIES OF Pseudopiptadenia contorta (Leguminosae) AND OF QUEBRACHO (Schinopsis sp.) EXTRACTS. Proanthocyanidins from P. contorta leaves and from a commercial quebracho extract were isolated and characterized. Flavonoids, catechins and gallic acid were also identified in the extracts of $P$. contorta. Compounds were evaluated for their antioxidant properties and for their antiviral activity against an acyclovir-resistant herpes simplex virus type 1 strain. The low molecular weight phenolic derivatives and the proanthocyanidins from P. contorta showed the highest antioxidant activity. Purified proanthocyanidins from both $P$. contorta and quebracho showed the same maximum non toxic concentrations $(25 \mu \mathrm{g} /$ $\mathrm{mL}$ ), with $82.2 \%$ and $100 \%$ of virus inhibition, respectively.
\end{abstract}

Keywords: Pseudopiptadenia contorta; quebracho tannins; antiviral activity.

\section{INTRODUCTION}

Pseudopiptadenia contorta is a tree commonly found in the Brazilian Atlantic Forest. This species belongs to the family Leguminosae that is composed of ca. 650 genera and 18,000 species $^{1}$. In a previous work, concerning the analysis of phenolics from plants of the diet of a group of Howler monkeys (Alouatta fusca), high amounts of proanthocyanidins were found in the $P$. contorta leaf extract ${ }^{2}$. In that study commercial quebracho tannins were isolated in order to build a calibration curve for proanthocyanidins analysis ${ }^{3}$. Also, in another project that focused on the search for antioxidative agents from Brazilian natural sources $P$. contorta pointed out as one of the most active extracts ${ }^{4}$. Proanthocyanidins and related compounds (catechins) are well known for their biological properties, encompassing antiviral, anticancer, antioxidant and antimicrobial activities ${ }^{5-7}$. This work describes the isolation and structural analyses of proanthocyanidins and flavonoids from $P$. contorta leaves and from a commercial quebracho extract, the evaluation of their antioxidant properties, as well as their antiviral activity against an acyclovir-resistant herpes simplex virus type 1 strain.

\section{RESULTS AND DISCUSSION}

HPLC analysis with solvent system I of the crude acetone/water extract from the leaves of $P$. contorta showed signals mainly due to three major compounds at RT 3.5, 16.1 and $30.3 \mathrm{~min}$. Signals of proanthocyanidins were not observed in the chromatogram due to

*e-mail: ggleitao@nppn.ufrj.br their relative lower concentration in the extract and to their lower $\varepsilon$. Purification of this extract on Sephadex LH-20 afforded 6 fractions which were analysed by HPLC (solvent system I). Results showed the presence of one major compound in both fractions 1 $(\mathrm{RT}=16.1 \mathrm{~min})$ and $4(\mathrm{RT}=30.3 \mathrm{~min})$. The UV spectra of these compounds showed characteristic signals of a flavonol $\left(\lambda_{\max } 263\right.$ and $348 \mathrm{~nm}$ ) and of a chalcone $\left(\lambda_{\max } 240\right.$ and $\left.367 \mathrm{~nm}\right)$, respectively. Compounds in fractions 1 and 4 were purified by recrystalization in $n$-hexane and acetone. ${ }^{1} \mathrm{H}$ and ${ }^{13} \mathrm{C}$ NMR analyses (1D and 2D) allowed to identify the compound on fraction 1 as myricetin 3-O$\alpha$-L-rhamnopyranoside (myricetrin) and that on fraction 4 as 2',4dihydroxy-4'- $O$-methylchalcone ${ }^{8,9}$. Co-injection HPLC analysis (system I) of the crude extract with standards allowed to identify the signal at $3.5 \mathrm{~min}$ as gallic acid. By this means, the presence of gallic acid $(\mathrm{RT}=3.5 \mathrm{~min})$, catechin $(\mathrm{RT}=6.8 \mathrm{~min})$, epi-catechin $(\mathrm{RT}=9.8 \mathrm{~min})$, epi-catechin gallate and catechin gallate $(\mathrm{RT}=11.5$ and $13.8 \mathrm{~min}$, respectively) was also shown in fraction 6 (ethyl acetate fraction). The proanthocyanidin rich fractions of $P$. contorta (fraction 5) and of quebracho tannins were also analysed by HPLC using solvent system $\mathrm{II}^{10}$. This analysis showed signals at 23 and $35 \mathrm{~min}$. The UV spectra of each signal showed $\lambda_{\max }$ at $278 \mathrm{~nm}$ suggesting the presence of oligomeric and polymeric flavanols ${ }^{10}$. Fraction 5, which presumably contained proanthocyanidins of $P$. contorta, and the equivalent fraction of quebracho tannins were submitted to $\mathrm{BuOH}-\mathrm{HCl}$ hydrolysis giving a deep red coloration, which confirmed their presence ${ }^{3}$. The hydrolysis products were analysed by TLC on cellulose with standards, allowing the identification of cyanidin as the major compound for both plants. These results show that both proanthocyanidins are constituted exclusively by catechin or epi-catechin. Vanillin and $\mathrm{BuOH}-\mathrm{HCl}$ 
(proanthocyanidin assay) reactions were used to evaluate the polymer length (PL) of these proanthocyanidin fractions. The results from the proanthocyanidin assay refer to the length of the condensed tannin while the vanillin assay is associated with steric hindrance. By this means, the ratio of the absorbance of a sample in the proanthocyanidin assay to that in vanillin assay rises as polymer length rises ${ }^{3} . P$. contorta gave a PL of 3.33 while quebracho gave a PL of 1.58. These results indicate that $P$. contorta proanthocyanidins are twice longer and/or have more C4-C6 linkage (easier to break than C4-C8) than those of quebracho ${ }^{3}$. Phloroglucinol was investigated as an alternative cleavage reagent in the structural study of proanthocyanidins ${ }^{11}$. The proanthocyanidin fractions from $P$. contorta and from quebracho were reacted with phloroglucinol following exactly the same conditions described by Foo and Karchesy ${ }^{11}$ and the results are shown in Table 1. The reaction of the proanthocyanidins from $P$. contorta with phloroglucinol yielded as terminal unit mainly epi-catechin, while the extension units were identified as catechin-phloroglucinol and epi-catechinphloroglucinol in the ratio of about $3: 1$. The products of the reaction of the proanthocyanidins from quebracho with phloroglucinol afforded catechin and epi-catechin as terminal units, in the ratio of about 1:1; and catechin-phloroglucinol and epi-catechinphloroglucinol as extension units, in the ratio of about 1:3. Compounds (+)-catechin and (-)-epi-catechin were submitted separately to the same reactional mixture to evaluate the percentage of epimerization. For (+)-catechin, the rate of conversion was $13.5 \%$, while for epi-catechin it was $9.1 \%$. Thus, the conversion of (+)catechin to epi-catechin is higher and means that the percentage of epi-catechin is overestimated about $4 \%$. Gel permeation chromatography (GPC) of the acetylated proanthocyanidin derivatives was used to evaluate molecular weight average of these proanthocyanidin fractions ${ }^{12}$. For $P$. contorta proanthocyanidins a number average of 1361 was obtained, suggesting these polymers to be constituted by $c a .3$ monomer units (the molecular weight of a peracetate constituent unit is $c a$. 500). The proanthocyanidin fraction obtained from quebracho gave a number average of 967 , suggesting $c a .2$ units per structure. Comparing the results obtained from the two techniques, it is possible to note that there is a difference between PL and GPC analyses. This difference can be explained by the C4-C6 linkage between the monomer units that contributes to increase PL obtained for P. contorta.

Antioxidant activity (AA) measured for the $P$. contorta fractions, pure compounds and for the standards is reported in Table 2. The $P$. contorta crude acetone/water extract showed an AA comparable with that of rutin $(\mathrm{EC} 50=14.40$ and $12.90 \mu \mathrm{g} / \mathrm{mL}$, respectively). Myricetrin, purified from fraction 1 was more active than the crude extract $(\mathrm{EC} 50=7.67 \mu \mathrm{g} / \mathrm{mL})$ and rutin. Fractions 2 and 3 showed almost no activity in this assay (EC50 > $120 \mu \mathrm{g} / \mathrm{mL})$. However, the 2',4-dihydroxy-4'- $O$-methylchalcone purified from fraction 2 showed EC $50=31.35 \mu \mathrm{g} / \mathrm{mL}$, being less active than the crude extract. Fraction 5, rich in proanthocyanidins, was more active than the crude extract and rutin $(\mathrm{EC} 50=8.74 \mu \mathrm{g} / \mathrm{mL})$. The ethyl acetate fraction (fraction 6) was the most active of all (EC $50=6.30 \mu \mathrm{g}$ / $\mathrm{mL}$ ). Gallic acid and catechin standards were also tested and showed the best AA results (Table 2). These results are in agreement with the literature data ${ }^{13}$ and justify the AA of fraction 6 .

Tannins and flavonoids have revealed a variety of significant biological effects including antiviral and antitumoral activities in $v_{\text {vitro }}^{5}$. The inhibitory effect of plant extracts on herpes simplex virus replication is in part related to the rich content of polyphenolic compounds ${ }^{14}$. Antiviral and cytotoxic activities of the extract, fractions and pure compounds of $P$. contorta as well as the quebracho tannins against $\mathrm{ACV}^{\mathrm{R}}-\mathrm{HSV}-1$ propagated in HEp-2 cells are shown in Table 2. The acetone/water extract from P.contorta was more active than the fractions showing $99.4 \%$ of inhibition at the maximun non toxic concentration (MNTC) of $100 \mu \mathrm{g} / \mathrm{mL}$. The flavonoid rutin,

Table 1. Characterization of proanthocyanidins from P. contorta (PC) and from quebracho (QB) determined by HPLC following phloroglucinol degradation

\begin{tabular}{|c|c|c|c|c|c|c|}
\hline \multirow[t]{2}{*}{ sample } & \multicolumn{2}{|c|}{ terminal units $(\%)$} & \multirow[t]{2}{*}{ ratio $\mathrm{CAT} / \mathrm{ECT}$} & \multicolumn{2}{|c|}{ extension units $(\%)$} & \multirow[t]{2}{*}{ ratio CAT/ ECT } \\
\hline & CAT & ECT & & CAT & ECT & \\
\hline PC & traces & 94 & $0: 1$ & 73 & 27 & $3: 1$ \\
\hline QB & 57 & 43 & $1: 1$ & 24 & 76 & $1: 3$ \\
\hline
\end{tabular}

CAT = catechin; $\mathrm{ECT}=$ epi-catechin; values corresponding to the mean of triplicate analyses.

Table 2. Antioxidant activity (AA) and anti-HSV-1 activities of the extracts, fractions and compounds of $P$. contorta and of quebracho

\begin{tabular}{|c|c|c|c|}
\hline Material & MNTC $(\mu \mathrm{g} / \mathrm{mL})$ & $\mathrm{PI} \%$ & $\mathrm{AA}(\mathrm{EC} 50 \mu \mathrm{g} / \mathrm{mL}) \pm \mathrm{SD}$ \\
\hline \multicolumn{4}{|l|}{ P. contorta } \\
\hline acetone/water 7:3 extract & 100 & 99.4 & $14.40 \pm 0.29$ \\
\hline \multicolumn{4}{|l|}{ Fractions from $P$. contorta } \\
\hline myricetrin (from fraction 1) & 25 & 52.1 & $7.67 \pm 0.31$ \\
\hline 2 & 100 & 43.8 & a \\
\hline 3 & 100 & 56.3 & $146.76 \pm 4.38$ \\
\hline 4 (chalcone) & 100 & 0.00 & $31.35 \pm 0.63$ \\
\hline 5 (purified proanthocyanidins) & 25 & 82.2 & $8.74 \pm 0.26$ \\
\hline 6 & 6.25 & 29.2 & $6.30 \pm 0.19$ \\
\hline quebracho proanthocyanidins & 25 & 100.0 & $6.70 \pm 0.21$ \\
\hline gallic acid* & 12.5 & 74.9 & $2.67 \pm 0.08$ \\
\hline catechin* & 200 & 55.3 & $3.41 \pm 0.13$ \\
\hline epi-catechin* & 200 & 0.00 & $3.36 \pm 0.10$ \\
\hline rutin* & 200 & 60.2 & $12.90 \pm 0.39$ \\
\hline
\end{tabular}

*Standards; MNTC = Maximum non-toxic concentration; PI = percentage of inhibition; ${ }^{\text {a }}$ EC $50>250 \mu \mathrm{g} / \mathrm{mL}$ 
used as standard, was less active (60.2\%). Gallic acid exhibited a higher cytotoxicity $(12.5 \mu \mathrm{g} / \mathrm{mL})$ than the extract with $\mathrm{ACV}^{\mathrm{R}}-\mathrm{HSV}$ 1 inhibition of $74.9 \%$. Epi-catechin presented no antiviral effect at all while catechin and myricetrin had moderate similar effects showing 55.3 and $52.1 \%$ of inhibition, respectively. Nevertheless, myricetrin was more toxic $(25 \mu \mathrm{g} / \mathrm{mL})$ than catechin $(200 \mu \mathrm{g} / \mathrm{mL})$. It is interesting to compare the antiviral results obtained for catechin and epi-catechin. Although they differ only in one chiral center (epimers) they show quite different percentages of inhibition (PI) at the same MNTC - Table 2. Takechi et al. ${ }^{15}$ have assayed a variety of condensed and hydrolysable tannins for antiherpetic activity. Their results with all tested epi-catechin derivatives [(-)-epicatechin, and galloyl derivatives of (-)-epi-catechin and (-)-epigallocatechin] were similar to our results, showing little, if none, activity. However, they did not assay catechin itself, which showed a percentage of inhibition of $55.3 \%$ in our assays.

Purified proanthocyanidins from both $P$. contorta and quebracho showed the same MNTC $(25 \mu \mathrm{g} / \mathrm{mL})$. Nevertheless, those of quebracho were the most active showing $100 \%$ of inhibition. Fraction 5 also had a significant effect (82.2\%).

The antiviral activity of tannins may be based on their interaction to proteins of cell surface and virus protein ${ }^{16}$ resulting in inhibition of viral attachment and penetration of the plasma membrane ${ }^{17}$. In fact, the proanthocyanidins from $P$. contorta and quebracho exhibited high $\mathrm{ACV}^{\mathrm{R}}$-HSV-1 inhibition at low concentration. Quebracho tannins had a better inhibition effect than those from $P$. contorta.

Takechi et al. ${ }^{15}$ investigating the relationship between the antiherpetic activity and structure of tannins observed that the activity of proanthocyanidins increased with the degree of condensation (ranging from 2 to 4 units). SP-303, a proanthocyanidin with an average chain length of seven units composed of four related catechin and gallocatechin stereoisomers, from the latex of Croton lechleri (Sangre de Drago), showed significant inhibitory activity against herpes simplex virus types 1 and 2 , including resistant-acyclovir and -foscarnet strains ${ }^{17}$. Controversially, although the proanthocyanidins of quebracho were twice shorter than those of $P$. contorta they were more active. As the proanthocyanidins of $P$. contorta contain only epi-catechin as terminal unit this could suggest that the lower antiviral activity of this extract could, in part, be due to the presence of this monomer, since epi-catechin standard showed no activity in our experiments. On the other hand, it could be suggested that being smaller, quebracho tannins could penetrate the cell and show an intracellular mechanism of action. In fact, when they were added after the cell infection, an antiviral effect was observed (data not shown). Experiments are being performed to elucidate the intracellular mechanism of action of the quebracho tannins.

\section{MATERIALS AND METHODS}

\section{General experimental procedures}

NMR spectra were recorded on a Varian Gemini-200 MHz and on a Bruker $400 \mathrm{MHz}$ instrument. Chemical shifts were referenced to the solvent signal. Analytical HPLC was carried out in a Lachrom (Merck-Hitashi) apparatus (L-7100), equipped with a DAD detector (L-7450). UV spectra and measurements were recorded on a Shimadzu apparatus. Sephadex LH-20 was from Pharmacia. The following chemical compounds were obtained from Sigma: gallic acid (G-7384); (+)-catechin (C-0567); (-)-epi-catechin (E1753); (-)-catechin gallate (C-0692); (-)-epi-catechin gallate (E-3893); quercetin (Q0125). Rutin was from Merck (159664). DPPH (2,2diphenyl-1-pycryl-hydrazyl radical) was from Aldrich Chem Co.
(1898-66-4). Quebracho extract (obtained from Schinopsis sp.) was provided by Dr. A. Haggerman, and was purified as described below (see extraction and isolation).

\section{Plant material}

Leaves of Pseudopiptadenia contorta (DC.) G.P. Lewis \& M.P. Lima were collected at Mata Boa Vista, at the locality of Levy Gaspariam, Três Rios District, Rio de Janeiro State, Brazil, in 1995. The plant material was identified by H. Lima and a voucher specimen has been deposited at the herbarium of Museu Nacional/ UFRJ, Rio de Janeiro, Brazil.

\section{Extraction and isolation}

Dried and ground leaves $(1.8 \mathrm{~kg}$ ) of Pseudopiptadenia contorta were extracted with a mixture of acetone/water (7:3) at room temperature. The acetone was removed under reduced pressure and the resulting material was lyophilized $(60 \mathrm{~g})$. A sample of the dried extract (500 mg) was purified on a Sephadex LH-20 column, initially eluted with ethanol $95 \%$ and then with acetone/water 1:1. A total of 5 fractions were collected. Fraction 5 (acetone/water 1:1) was evaporated under reduced pressure to remove the acetone and then partitioned between ethyl acetate and water. The ethyl acetate was removed under reduced pressure to afford fraction 6 , and the remaining aqueous solution (fraction 5) contained the purified proanthocyanidins. Fraction 1 afforded myricetrin $(12 \mathrm{mg})$, fraction 4 afforded 2',4-dihydroxy-4'- $O$-methylchalcone (45 mg), fraction 5 afforded the proanthocyanidins $(30 \mathrm{mg}$ ) and fraction 6 afforded a mixture of catechins $(15 \mathrm{mg})$. An extract obtained from quebracho was purified using the same methodology.

\section{HPLC analysis}

Stock solutions of $1 \mathrm{mg} / \mathrm{mL}$ of the $P$. contorta extracts and fractions were prepared before analysis. A Lachron Merck HPLC was used equipped with a Lichrosorb RP 18 column ( $5 \mu \mathrm{m}$ particle size, $250 \times 4 \mathrm{~mm}$ id); flow of $1 \mathrm{~mL} / \mathrm{min}$; chromatographic analyses were run with system I: gradient of acetic acid $1 \%$ in water (solvent A) and $\mathrm{MeOH}$ (solvent B): 0 min, 20\% B; 0-30 min, 80\% B linear; $30-31 \mathrm{~min}, 100 \% \mathrm{~B}$ linear; $31-40 \mathrm{~min}, 100 \% \mathrm{~B}$ isocratic, followed by column washing and reconditioning for $10 \mathrm{~min}$; system II: gradient of acetic acid $2.5 \%$ in water (solvent $\mathrm{A}$ ) and $\mathrm{CH}_{3} \mathrm{CN}$ (solvent B): 0-3 min, 3\% B isocratic; 3-13 min, 9\% B linear; 13-18 min, 11\% B linear; 18-25 min, 18\% B linear; 25-30 min, 18\% B isocratic; 30-45, 30\% B linear, followed by column washing and reconditioning for $10 \mathrm{~min}$. Detection: DAD detector Lachron Merck $7750 \mathrm{~A}$; integration of the signal at $270-280 \mathrm{~nm}$ fixed wavelength.

\section{Phloroglucinol degradation}

Purified proanthocyanidins $(5 \mathrm{mg}$ ) were dissolved in $750 \mu \mathrm{L}$ of freshly prepared phloroglucinol solution $(5 \mathrm{mg} / \mathrm{mL}$ in ethanol/ $\mathrm{HCl}$ $1 \%$ ) in a screw tube. This solution was allowed to react at room temperature for $24 \mathrm{~h}$. The solvent was then evaporated under nitrogen, and the residue dissolved in $250 \mu \mathrm{L}$ distilled water. The obtained solution was extracted three times with ethyl acetate ( $750 \mu \mathrm{L}$ per extraction). The ethyl acetate fractions were combined and evaporated under $\mathrm{N}_{2}$. The residue was dissolved in $300 \mu \mathrm{L}$ of methanol and then analysed by HPLC. The same column and apparatus as for the analyses of $P$. contorta extract and fractions were used. Mobile phase A - acetic acid $1 \%$ in water; mobile phase B - methanol $60 \%$ and solvent A 40\%; gradient conditions: A $100 \%$ 
to A $40 \%$ / B $60 \%$ in 60 min and then B $100 \%$ in 5 min, followed by column washing and reconditioning for $10 \mathrm{~min}$. The phloroglucinol products were identified in the chromatograms by their retention times (RT) and UV spectra and the catechins were identified by co-injections with pure standards.

\section{Polymer length (BuOH-HCl Hydrolysis/Vanillin Assay)}

Samples of purified proanthocyanidins $(5 \mathrm{mg}$ ) from quebracho and $P$. contorta were dissolved in $10 \mathrm{~mL}$ of $\mathrm{MeOH}$. One aliquot of this solution $(1 \mathrm{~mL})$ was reacted with $4 \mathrm{~mL}$ of $\mathrm{BuOH}-\mathrm{HCl} 5 \%$ in sealed tubes for $2 \mathrm{~h}$ in water bath $\left(95^{\circ} \mathrm{C}\right)$. Absorbance values of the obtained cyanidin were measured at $540 \mathrm{~nm}$. Another aliquot of the solution $(1 \mathrm{~mL})$ was reacted with $4 \mathrm{~mL}$ of acidic vanillin solution $(0.5 \%$ in $\mathrm{MeOH}-\mathrm{HCl} 4 \%)$ at $30{ }^{\circ} \mathrm{C}$ for $20 \mathrm{~min}$. Absorbance values were measured at $500 \mathrm{~nm}$. All analyses were performed in triplicate and the polymer length (PL) was evaluated by the ratio of $\mathrm{BuOH}-$ $\mathrm{HCl}$ and vanillin absorbance values.

\section{TLC analysis}

TLC analysis of the $\mathrm{BuOH}-\mathrm{HCl}$ hydrolysis products was performed with Merck cellulose plates that were developed with butanol, acetic acid and water solution 4:1:5. The plates were visualized by $\mathrm{UV}$ at 254 and $365 \mathrm{~nm}$ and by spraying with a $5 \%$ vanillin solution in $10 \% \mathrm{HCl}$ in ethanol $(\mathrm{v} / \mathrm{v})$, followed by heating the plate. A sample of catechin $(5 \mathrm{mg}$ ) was also submitted to the reaction with $\mathrm{BuOH}-\mathrm{HCl} 5 \%$ to give cyanidin, used as standard for TLC analysis.

\section{Molecular weight average}

Gel permeation chromatography (GPC) analyses were carried out on a Waters 600E model equipped with two heads pump and with two Ultrastyragel ${ }^{\mathrm{TM}}$ columns (porosity of $500 \AA$ ) connected in series. A refractive index (RI) detector from Waters (model 410) was used. All analyses were run in isocratic flow of $1 \mathrm{~mL} / \mathrm{min}$, using THF as solvent. Calibration curves were obtained using polystyrene standards. The fractions containing the $P$. contorta and quebracho proanthocyanidins $(10 \mathrm{mg})$ were acetylated with pyridine- $\mathrm{Ac}_{2} \mathrm{O}$ (1:1). After standing overnight, the reaction mixture was evaporated under $\mathrm{N}_{2}$, redissolved in water and the products were extracted with chloroform. The chloroform fraction was evaporated with $\mathrm{N}_{2}$ and about 2-5 mg tannin peracetate was used.

\section{DPPH photometric assay}

Sample stock solutions $(1.0 \mathrm{mg} / \mathrm{mL})$ were diluted to final concentrations of $250,125,50,25,10$ and $5 \mu \mathrm{g} / \mathrm{mL}$, in ethanol. One $\mathrm{ml}$ of a $0.3 \mathrm{mM}$ DPPH ethanolic solution was added to $2.5 \mathrm{~mL}$ of sample solutions of different concentrations, and allowed to react at room temperature. After $30 \mathrm{~min}$ the absorbance values were measured at $518 \mathrm{~nm}$ and converted into percentage of antioxidant activity (AA) using the following formula: AA\% $=100$ $\left\{\left[\left(\mathrm{ABS}_{\text {SAMPLE }}-\mathrm{ABS}_{\text {BLANK }}\right) \mathrm{X} 100\right] / \mathrm{ABS}_{\text {ControL }}\right\}$. Ethanol $(1.0 \mathrm{~mL})$ plus plant extract solution $(2.5 \mathrm{~mL})$ was used as blank. DPPH solution $(1.0 \mathrm{~mL} ; 0.3 \mathrm{mM})$ plus ethanol $(2.5 \mathrm{~mL})$ was used as negative control. The positive controls were those using the standard solutions of gallic acid, (+)-catechin, (-)-epi-catechin and rutin. The EC50 values were calculated by linear regression of plots where the abscissa represented the concentration of tested plant extracts and the ordinate the average percent of antioxidant activity from three separated tests ${ }^{4}$.

\section{Cell culture and virus}

HEp-2 cells (human larynx carcinoma cell line) were cultivated in Eagle's minimum essential medium (Eagle-MEM) supplemented with $5 \%$ fetal bovine serum, garamicin and fungizon ${ }^{18}$. The cell cultures were prepared in 96-well plastic microtiter plates and incubated in $5 \% \mathrm{CO}_{2}$ atmosphere at $37{ }^{\circ} \mathrm{C}$. Acyclovir-resistant herpes simplex virus type $1\left(\mathrm{ACV}^{\mathrm{R}}-\mathrm{HSV}-1\right)$ was isolated in our laboratory from a typical labial lesion and propagated in HEp-2 cell line ${ }^{19}$.

\section{Sample preparation for antiviral assay}

Extracts and fractions, as well as standards were solubilized in dimethyl sulphoxide (final concentration 1\%) and diluted in EagleMEM without serum to a final concentration of $200 \mu \mathrm{g} / \mathrm{mL}$. The solution was sterilized by filtration using $0.22 \mu \mathrm{m}$ Millipore membrane, aliquoted and stored at $-20^{\circ} \mathrm{C}$.

\section{Determination of the maximum non-toxic concentration}

The maximum non-toxic concentrations (MNTC) of each sample were determined by a method similar to that described by Walker et al. ${ }^{20}$ that is based in cellular morphologic alterations. Several concentrations of each sample were placed in contact with confluent HEp-2 cell monolayers and incubated in $5 \% \mathrm{CO}_{2}$ atmosphere at $37{ }^{\circ} \mathrm{C}$ for five days. At the end of this time the cells were examined by microscopy and the maximum non-toxic concentration (MNTC) of each sample was determined. A toxicity control of the solvent (DMSO) in the concentration used was included.

\section{Determination of the antiviral activity}

The antiviral activity was achieved by the reduction of the virus titers $\left(\mathrm{TCID}_{50}\right)$ determinations. The HEp-2 cell monolayers cultivated in 96-well-microplates were treated with two-fold dilutions of the extracts and fractions beginning from the MNTC. Immediately after, logarithmical dilutions of $\mathrm{ACV}^{\mathrm{R}}$-HSV-1 were added to the treated and untreated cell cultures and incubated in $5 \% \mathrm{CO}_{2}$ atmosphere at $37^{\circ} \mathrm{C}$. After five days of incubation the virus titer was calculated by the Reed and Muench ${ }^{21}$ statistical method and expressed in $\mathrm{TCID}_{50}$. The results were expressed in percentage of inhibition (PI) ${ }^{22}$ using antilogarithmic values of $\mathrm{TCID}_{50}$ as follows: $\mathrm{PI}=(1-\mathrm{T}$ antilogarithm/C antilogarithm $) \times 100$, where $\mathrm{T}$ is virus titer on treated cells (test) and $\mathrm{C}$ is virus titer on untreated cells (control). Experiments were made in triplicates.

\section{AKNOWLEDGEMENTS}

We are indebted to J. B. Tostes from NPPN-UFRJ and to Prof. Dr. E. Ermel from IMA-UFRJ, for peracetylation of purified proanthocyanidins samples and for GPC analysis. This work was partially supported by Grant PRONABIO no.214/98 from Ministério do Meio Ambiente (MMA/CNPq/BIRD), Brazil. M. D. Wigg wishes to thank CNPq, FAPERJ and FINEP for support.

\section{REFERENCES}

1. Barroso, G. M.; Sistemática de Angiospermae do Brasil, EDUSP: São Paulo, 1978, vol. I.

2. Leitão, G. G.; Mensor, L. L.; Amaral, L. F. G.; Floriano, N.; Limeira, V. L. G.; Menezes, F. S.; Leitão, S. G. In Plant Polyphenols 2: Chemistry, Biology, Pharmacology and Ecology; Hemingway, R.; Gross, G. G.; Yoshida, T., eds.; Plenum Press: New York, 1999, p. 883-895. 
3. Waterman, P. G.; Mole, S.; Analysis of Plant Metabolites, Blackwell Scientific Publications: Oxford, 1994, chap. 4, p. 66-103.

4. Mensor, L. L.; Menezes, F. S.; Leitão, G. G.; Reis, A. S.; Coube, C. S.; dos Santos, T. C.; Leitão, S. G.; Phytother. Res. 2001, 15, 127.

5. Haslam E.; J. Nat. Prod. 1996, 59, 205.

6. Bagchi, D.; Bagshi, M.; Stohs, S. J.; Das, D. K.; Ray, S. D.; Kuszynski, C. A.; Joshi, S. S.; Pruess, H. G.; Toxicology 2000, 147, 187.

7. Foo, L. Y.; Lu, Y.; Howell, A. B.; Vorsa, N.; J. Nat. Prod. 2000, 63, 1225.

8. Mabry, J. T.; Markhan, K. R.; Thomas, M. B.; Systematic Identification of Flavonoids, Springer-Verlag: New York, 1970, p. 102, 165, 309, 335.

9. Agrawal, P. K.; Carbon-13 NMR of Flavonoids, Elsevier: New York, 1989, p. $304,338,378$.

10. Guyot, S.; Doco, T.; Souquet, J-M.; Moutounet, M.; Drilleau, J-F.; Phytochemistry 1997, 44, 351.

11. Foo, L. Y.; Karchesy, J.; Phytochemistry 1989, 28, 3185.

12. Williams, V. M.; Porter, L. J.; Hemingway, W.; Phytochemistry 1983, 22, 569.

13. Yoshida, T.; Mori, K.; Hatano, T.; Okumura, T.; Uehara, I.; Komagoe, K.; Fugita, Y.; Okuda, T.; Chem. Pharm. Bull. 1989, 37, 1919.

14. Serkedjieva, J.; Ivancheva, S.; J. Ethnopharmacol. 1999, 64, 59.
15. Takechi, M.; Tanaka, Y.; Takehara, M.; Nonaka, G.; Nishioka, I.; Phytochemistry 1985, 24, 2245.

16. De Bruyne, T.; Pieters, L.; Deelstra, H.; Vlietinck, A.; Biochem. Syst. Ecol. 1999, 27, 445.

17. Ubillas, R.; Jolad, S. D.; Bruening, R. C.; Kernan, M. R.; King, S. R.; Sesin, D. F.; Barret, M.; Stoddart, C. A.; Flaster, T.; Kuo, J.; Ayala, F.; Meza, E.; Castañel, M.; McMeekin, D.; Rozhon, E.; Tempesta, M. S.; Barnard, D.; Huffman, J.; Smee, D.; Sidwell, R.; Soike, K.; Brazier, A.; Safrin, S.; Orlando, R.; Kenny, P. M. T.; Berova, N.; Nakanishi, K.; Phytomedicine 1994, 1,77 .

18. Schmidt, N.J. In Diagnostic procedures for viral and rickettsial infections; Lennette, E. H.; Schmidt, N. J., eds.; Amer. Pub. Health Assoc. Inc.: New York, $5^{\text {th }}$ ed., 1979 , p. 65-139.

19. Miranda, M. M. F. S.; Almeida, A. P.; Costa, S. S.; Santos, M. G. M.; Lagrota, M. H. C.; Wigg, M. D.; Phytomedicine 1997, 4, 347.

20. Walker, W. E.; Waisbren, B. A.; Martins, R. R.; Batayias, G. E.; Am. J. Clin. Path. 1971, 56, 687.

21. Reed, L. J.; Muench, H.; Am. J. Hyg. 1938, 27, 493.

22. Nishimura, T.; Toku, K.; Fukuyasu, H.; Kitasato Arch. Exp. Med. 1977, $50,39$. 